\title{
O PRINCÍPIO GERAL DA PROGRESSIVIDADE NO SISTEMA TRIBUTÁRIO NACIONAL* \\ THE GENERAL STANDARD OF PROGRESSIVITY AT NATIONAL TAX SYSTEM
}

\author{
Laís Gramacho Colares**
}

\begin{abstract}
Resumo: A progressividade tributária é, muitas vezes, concebida como regra ou técnica de tributação restrita a alguns impostos, conforme se verifica, inclusive, da sua previsão na CF/88. No entanto, ao interpretar o Sistema Tributário Nacional integrado com os objetivos fundamentais da República Federativa do Brasil, pode-se identificar que a progressividade é um princípio geral do Sistema, decorrente da própria função dos tributos. Deve, assim, ser concebido como uma pauta a ser concretizada, sistematicamente, na maior medida possível.
\end{abstract}

Palavras-Chave: Progressividade; Princípio; Sistema Tributário.

\begin{abstract}
The progressive taxation is often conceived as a rule or a technique of taxation restricted to some taxes according to the CF/88 (National Constitution Letter). However, while interpreting the National Tax System alongside with the fundamental objectives of the Federative Republic of Brazil, it can be verified that that progressive taxation is a general standard of the System. Therefore, progressive taxation should be considered a standard and should be implemented systematically throughout the whole national taxation system.
\end{abstract}

Keywords: Progressivity; Standard; Tax System.

\section{INTRODUÇÃO}

A progressividade, ora concebida como princípio, ora como regra do Sistema Tributário Nacional, apenas foi prevista pela Constituição Federal de 1988 em caráter bastante pontual, em relação a alguns impostos.

Isso refletiu o posicionamento da jurisprudência do Supremo Tribunal Federal, por certo período de tempo, através de uma interpretação literal do texto constitucional.

Em precedentes mais recentes, o Supremo Tribunal Federal acabou reconhecendo a regularidade de adoção da regra da progressividade para alguns outros impostos, à mercê de qualquer previsão expressa da Constituição, o que, possivelmente, representa uma mudança de paradigma.

O presente artigo pretende demonstrar que, além da regra de progressividade expressamente previstas na Constituição Federal, em relação a alguns tributos, é possível identificar

\footnotetext{
*Artigo submetido em 18 jul. 2018 e aceito para publicação em 14 nov. 2018. Publicado em 19.12.2018.

${ }^{* *}$ Advogada, Doutoranda em Direito pela Universidade do Estado do Rio de Janeiro, Rio de Janeiro, Rio de Janeiro, Brasil. $\triangle$ lais.gramacho@gmail.com
} 
um princípio geral da progressividade, implícito no Sistema Tributário Nacional, como decorrência da função precípua dos tributos, em consonância com os objetivos fundamentais do Estado brasileiro.

Como princípio geral e implícito, investigar-se-á o seu conteúdo e alcance na presente ordem constitucional, tecendo sobretudo uma crítica a sua sistemática violação, pela forma como está construído o Sistema Tributário Brasileiro, principalmente no que diz respeito à distribuição da carga tributária pelas faixas de rendas dos cidadãos.

Para cumprir com esse objetivo, a abordagem se iniciará com a concepção atual, comum e explícita sobre a progressividade na Constituição Federal de 1988, uma abordagem, portanto, mais dogmática. Posteriormente, investigar-se-á a possibilidade de adoção da estrutura de princípio para a norma jurídica da progressividade, extraindo-se o seu conteúdo implícito, a partir de outros princípios constitucionais. Neste tópico, a abordagem dogmática será influenciada por fundamentos filosóficomorais. Por fim, demonstrar-se-á como a progressividade se configura um princípio geral informador de todo o Sistema Tributário Nacional e como a forma adotada pelo atual sistema viola, portanto, esse princípio geral.

Para isso, adotar-se-á o método lógico-dedutivo, a fim de identificar premissas criteriosas que levem à identificação da progressividade como um princípio do sistema jurídico tributário, utilizando-se de sopesamento com outros valores e princípios, além dos dados disponíveis para auxiliar o desenvolvimento proposto.

Será utilizada a doutrina nacional e estrangeira, tanto provenientes de estudos jurídicos, como econômicos e filosóficos, assim como dados provenientes de pesquisas já realizadas. Parte-se de uma concepção social e igualitária que concatena o tributo como instrumento para realização dos fins estatais, tanto sob o prisma da justiça fisscal, como da justiça social.

\section{A REGRA DA PROGRESSIVIDADE NA CONSTITUIÇÃO DE 1988}

Pode-se dizer que, apesar de alguns representantes da doutrina do Direito Tributário a denominarem como princípio $^{1}$, em sua previsão constitucional, a norma da progressividade é trazida com estrutura de regra. As regras podem ser concebidas como normas que possuem maior rigidez, descritivas de comportamentos devidos ou atributivas de poder ${ }^{2}$.

\footnotetext{
${ }^{1}$ Ricardo Lobo Torres faz referência ao princípio da progressividade. TORRES, Ricardo Lobo. Tratado de Direito Constitucional Financeiro e Tributário: Valores e princípios constitucionais tributários. Volume II. Rio de Janeiro: Renovar, 2014. p. 326. Luís Eduardo Schoueri ressalta que "[...] esses critérios são denominados correntemente 'princípios [...]", mas são, em verdade "[...] meras opções constitucionais ou legais [...]". No entanto, entende que "[...] não há razão para deixar de utilizar a expressão "Princípio" (com letra maiúscula) [...]". SCHOUERI, Luís Eduardo. Direito Tributário. 7. ed. São Paulo: Saraiva, 2017. p. 401.

2 ÁVILA, Humberto. Teoria dos princípios: da definição à aplicação de princípios jurídicos. 4. ed. São Paulo: Malheiros, 2005. p. 89.
} 
A Constituição Federal de 1988, quando tratou do imposto sobre a renda e proventos de qualquer natureza (IR), determinou que este será informado pelo "critério" da progressividade (art. $153, \S 1^{\circ}, \mathrm{I}$, da CF). No que diz respeito ao imposto sobre a propriedade rural (ITR), determinou que ele "[...] será progressivo e terá suas alíquotas fixadas de forma a desestimular a manutenção de propriedades improdutivas" (art. 153, $\S 4^{\circ}$, I, da CF). Quanto ao imposto sobre a propriedade predial e territorial urbana (IPTU), previu que este será progressivo em razão do valor do imóvel (art. 156, $\S 1^{\circ}$, I, da CF), previsão esta incluída pela Emenda à Constituição $n^{\circ} 29$ de 2000, além de ser progressivo no tempo, quando não estiver cumprindo a função social da propriedade nem o parcelamento compulsório (art. 182, §4 $4^{\circ}$ II, da CF).

De acordo com o dicionário da língua portuguesa, "progressivo" significa aquilo "que tem desenvolvimento gradual”, "que faz progressos", "que representa uma evolução, ou até "que se torna cada vez maior"3.

Em termos de ciências econômicas e sociais, pode-se dizer que "[...] um imposto é progressivo se a sua "taxa" é mais alta para os mais ricos e mais baixa para os mais pobres"

Juridicamente, verifica-se, em geral, a progressividade em uma razão existente entre a alíquota e a base de cálculo de determinado tributo. Assim, no caso de um imposto progressivo, a sua alíquota percentual crescerá conforme cresça a base de cálculo. O contrário aconteceria se o imposto fosse regressivo e seria proporcional se a alíquota percentual permanecesse idêntica, pouco importando o valor da base de cálculo ${ }^{5}$.

Neste sentido, a Constituição efetivamente só prevê a progressividade como critério para definição das alíquotas do imposto sobre a renda e proventos de qualquer natureza e do imposto sobre a propriedade predial e territorial urbana. Em relação ao imposto sobre a propriedade territorial rural, a progressividade prevista não trata de uma elevação da alíquota, em razão do aumento da base de cálculo, mas sim de um mecanismo para estimular a função social da propriedade rural. Neste último caso, a progressividade se verifica quando a alíquota varia em razão da produtividade ou não da propriedade rural.

Em todos os casos, portanto, a progressividade funciona como uma técnica para a definição dos aspectos quantitativos da obrigação tributária (alíquota, em função da base de cálculo ou de algum comportamento esperado do proprietário de bens imóveis).

Provavelmente em razão dessas previsões constitucionais, sua interpretação, inicialmente, deu-se de forma bem literal, aplicando-se apenas nos casos específicos em que há

\footnotetext{
${ }^{3}$ Disponível em: $<$ http://michaelis.uol.com.br/moderno-portugues/busca/portugues-brasileiro/progressivo/ $>$. Acesso em 1 fev. 2018.

${ }^{4}$ PIKETTY, Thomas. O Capital no século XXI. Trad. Monica Baumgarten De Bolle. Rio de Janeiro: Intrínseca, 2014. p. 482.

${ }^{5}$ SCHOUERI, Luís Eduardo. Direito Tributário. 7. ed. São Paulo: Saraiva, 2017. p. 401.
} 
previsão expressa, conforme se verifica da posição consolidada do Supremo Tribunal Federal (STF) ao longo do tempo, a teor das Súmulas 656 e $668^{6}$. O STF, portanto, aplicava a progressividade mais de modo "tudo-ou-nada", como norma de definição da forma como o poder de tributar deveria ser exercido, de acordo com as expressas previsões constitucionais.

Apesar dos indícios de alteração desse posicionamento recentemente, como se verificará adiante, pode-se perceber que a progressividade não foi, em geral, concebida como um ideal ou diretriz no Sistema Tributário Nacional, nem foi interpretada como princípio geral do sistema.

\section{A PROGRESSIVIDADE COMO PRINCÍPIO}

A partir de uma união de definições de autores como Humberto Ávila ${ }^{7}$, Luís Roberto Barroso $^{8}$, Karl Larenz ${ }^{9}$, Robert Alexy ${ }^{10}$ e Ronald Dworkin ${ }^{11}$, podem-se conceber princípios como normas carregadas de ideias diretrizes valorativas para orientar (e vincular) o Estado e os indivíduos (seus destinatários) na criação e aplicação de outras normas, em busca de um "estado ideal das coisas". Podem, assim, ser concebidos, ao mesmo tempo, como normas finalísticas e como pautas de valoração.

Galledo Peragón concebe a progressividade como princípio e regra. Assim, a progressividade, em abstrato, é um princípio que informa o sistema tributário e que não pode ser dispensado se o objetivo é que o sistema seja justo. No entanto, em concreto, é um instrumento técnico que possibilita uma igualdade de fato ${ }^{12}$.

No ordenamento jurídico brasileiro, a progressividade foi prevista como regra, como técnica de tributação atinente a algumas figuras tributárias específicas, como visto no item anterior. Entretanto, a previsão da progressividade como princípio, em abstrato, como diretriz para alcançar um estado ideal de igualdade, não é necessária para reconhece-lo como parte do ordenamento jurídico brasileiro, uma vez que o fundamento moral e jurídico da tributação, este explícito na Constituição,

\footnotetext{
${ }^{6}$ Súmula 656 do STF: "É inconstitucional a lei que estabelece alíquotas progressivas para o imposto de transmissão inter vivos de bens imóveis - ITBI com base no valor venal do imóvel"; Súmula 668 do STF: "É inconstitucional a lei municipal que tenha estabelecido, antes da Emenda Constitucional 29/2000, alíquotas progressivas para o IPTU, salvo se destinada a assegurar o cumprimento da função social da propriedade urbana".

7 ÁVILA, Humberto. Teoria da Igualdade Tributária. São Paulo: Malheiros, 2009.

${ }^{8}$ BARROSO, Luís Roberto. Interpretação e aplicação da Constituição. 7 ed. São Paulo: Saraiva, 2009.

${ }^{9}$ LARENZ, Karl. Metodologia da ciência do direito. Tradução José Lamego. 3 ed. Lisboa: Fundação Calouste Gulbenkian, 1997.

${ }^{10}$ ALEXY, Robert. Teoria dos Direitos Fundamentais. Tradução por Virgílio Afonso da Silva. São Paulo: Editora Malheiros, 2008.

${ }^{11}$ DWORKIN, Ronald. Levando os direitos a sério. Tradução e Nelson Boeira. 3 ed. São Paulo: WMF Martins Fontes, 2010.

${ }^{12}$ GALLEDO PERAGÓN, José Manuel. Los principios materiales de justicia tributaria. Granada, 2003. p. 169.
} 
levam-nos à conclusão natural de que a progressividade é, sim, também um principio norteador de todo o sistema tributário ${ }^{13}$.

É óbvio que não se quer, assim, dizer que a previsão constitucional deste princípio não faria qualquer diferença, principalmente do ponto de vista interpretativo. O que não se pode é condicionar a sua aplicação à expressa previsão constitucional, o que, de acordo com Ricardo Lodi Ribeiro, esvazia mortalmente o princípio da capacidade contributiva”, no contexto do Estado Democrático de Direito ${ }^{14}$.

Assim, podemos entender que a progressividade pode ser, ao mesmo tempo, uma regra e um princípio. No caso do Sistema Tributário Nacional, sua estrutura de regra é indubitável. Entretanto, é necessário explicitar os fundamentos para que lhe possa atribuir, também, a estrutura de princípio.

\subsection{O FUNDAMENTO MORAL PARA O SISTEMA TRIBUTÁRIO NACIONAL}

A sociedade brasileira ainda é caracterizada por uma profunda desigualdade social. $\mathrm{O}$ modelo liberal adotado ainda permanece tímido no que diz respeito à exaustiva tentativa da filosofia política de equilibrar os princípios da liberdade e igualdade, principalmente este último, diante da influência de modelos capitalistas mais avançados desenvolvidos em sociedades atualmente menos desiguais.

Do ponto de vista do fundamento moral, a Constituição Federal jamais admitiria um ideal de justiça libertário, uma vez que impôs ao Estado o dever de "[...] erradicar a pobreza e a marginalização e reduzir as desigualdades sociais e regionais" (art. $3^{\circ}$, III, da Constituição Federal). Na mesma medida em que previu a garantia da liberdade, exigiu a promoção da igualdade, através do parâmetro da solidariedade.

O ideal moral de justiça a ser perseguido é um ideal liberal, mas no contexto do Estado Democrático Fiscal ${ }^{15}$, portanto, objetivando um equilíbrio entre a liberdade e igualdade, mas impondo, sobretudo, ações positivas do Estado na erradicação da pobreza e da marginalização, para reduzir as desigualdades. Pode-se afirmar, com base nisso, que o ideal perseguido pela Constituição é guiado por uma concepção liberal de tendências igualitárias.

\footnotetext{
${ }^{13}$ Para Galledo Peragón, "la constitucionalización de la progressividad devine a favor de su eficacia jurídica, por cuanto es un criterio informador del ordenamiento jurídico que no puede ser menospreciado". GALLEDO PERAGÓN, José Manuel. Los principios materiales de justicia tributaria. Granada, 2003. p. 169.

${ }^{14}$ RIBEIRO, Ricardo Lodi. Temas de direito constitucional tributário. Rio de Janeiro: Lumen Juris, 2009. p. 216.

${ }^{15}$ De acordo com Ricardo Lobo Torres, "No Estado Democrático Fiscal, a liberdade adquire a feição de igual liberdade e se caracteriza como a liberdade que se aproxima da justiça na mesma equação valorativa" TORRES, Ricardo Lobo. Tratado de Direito Constitucional Financeiro e Tributário: Valores e princípios constitucionais tributários. Volume II. Rio de Janeiro: Renovar, 2014. p. 80.
} 
De acordo com uma teoria da justiça pós-positivista, a ideia de justiça social oferece conteúdo que se aproxima da necessidade de redistribuição de rendas, protegendo os mais fracos, mais pobres etc., guiada por princípios como o da solidariedade ${ }^{16}$.

Nesse contexto é que entra o sistema tributário. Para Klaus Tipke e Jachim Lang, na escolha dos indicadores de capacidade contributiva, é importante saber para qual sociedade deve ser construído o sistema tributário: se a sociedade dá ênfase à redistribuição e à distribuição igualitária do capital, a tributação deve se dar mais cedo possível, antes do consumo; no entanto, se a sociedade for construída de acordo com os ideais liberais e individualistas, o Estado deve esperar até que o cidadão consuma (o Estado protege a poupança e o investimento, permitindo a formação do bem privado $)^{17}$.

No contexto social e econômico de concentração de riquezas, pode-se extrair o dever estatal de promover a redistribuição de riquezas e o critério de distribuição do ônus tributário, portanto, pode ser o “[...] princípio do sacrifício cada vez maior”, concebido por Liam Murphy e Thomas Nagel, de acordo com o qual "a tributação justa impõe fardos maiores aos mais ricos"18.

Não se deve, portanto, partir para a construção de um sistema tributário ideal apenas com base na ideia de justa distribuição das cargas. Essa questão não deve ser separada da questão de saber se o governo realiza ou não justiça distributiva ${ }^{19}$.

Essa não é uma constatação óbvia e muito menos acolhida pacificamente pela doutrina do Direito Tributário. Klaus Tipke e Joacquim Lang, por exemplo, distinguem justiça fiscal do que denominam de "postulado ético-social da redistribuição". Para os autores, a justiça fiscal somente se realiza a partir da imposição com base na capacidade contributiva. Já a correção das desigualdades por meio da imposição trata-se de normas com finalidade social. Entendem, portanto, que a adoção da justiça redistributiva pela imposição evapora a harmonia de propósitos de justiça fiscal e eficiência ${ }^{20}$.

No entanto, partindo da constatação empírica da profunda desigualdade social, caracterizada pela excessiva concentração de riquezas, de um lado, e pobreza e miséria, de outro, percebe-se que a iniciativa privada, sozinha, não promove redistribuição. Assim, “[...] a ideia de

\footnotetext{
${ }^{16}$ Ibidem. p. 112-119.

${ }^{17}$ TIPKE, Klaus. LANG, Joachim. Direito Tributário (Steurrecht). Volume I. Porto Alegre: Sergio Antonio Fabris Editor, 2008. p. 211.

${ }^{18}$ MURPHY, Liam; NAGEL, Thomas. O Mito da Propriedade: os impostos e a justiça. São Paulo: Martins Fontes, 2005. p. $42-43$.

${ }^{19}$ Idem. p. 21.

${ }^{20}$ É por isso que os autores entendem que a progressividade não resulta do princípio da capacidade contributiva. TIPKE, Klaus. LANG, Joachim. Direito Tributário (Steurrecht). Volume I. Porto Alegre: Sergio Antonio Fabris Editor, 2008. p. 395.
}

Revista de Finanças Públicas, Tributação e Desenvolvimento, v. 6, n. 7, julho/dezembro, 2018, p. 100-121. 
tributação de acordo com a capacidade contributiva é entendida em função da noção de que a justiça exige uma redistribuição outra que não a efetuada pelo mercado"21.

Ronald Dworkin afirma que duas grandes metáforas vêm sendo utilizadas pela filosofia política em grande escala para a teoria da justiça social: a metáfora do contrato social imaginário, que prevê a redistribuição dos ricos para os pobres; a metáfora de um conjunto de seguros para o qual os membros da sociedade contribuem e de onde os necessitados obtêm. Apesar de a metáfora do seguro ter sido muito menos utilizada pelos filósofos políticos, o autor considera que desempenha importante papel na política prática ${ }^{22}$.

$\mathrm{O}$ autor defende que os tributos que as pessoas pagam para financiar os programas sociais (contra acidentes, doenças, desemprego etc.) devem ser entendidos como seguro e os benefícios que as pessoas recebem (quando estão doentes, acidentadas, desempregadas ou necessitadas de alguma forma) como benefícios do seguro. Essa é, na visão do autor, uma reivindicação de igualdade $e x$ ante $^{23}$.

Descrever um programa social redistributivo como seguro sugere solidariedade social, ou seja, sugere que os cidadãos de uma comunidade política têm reafirmado sua identidade coletiva através do agrupamento de riscos que enfrentam ${ }^{24}$.

A concepção de igualdade de Dworkin, de acordo com a qual o Estado deve ter igual consideração com os seus cidadãos, coloca o sistema tributário no cerne das medidas distributivas/redistributivas. Assim, a adoção de determinada política tributária por um governo deve ter como fundamento moral tratar a todos com a mesma consideração, assumindo que tem as mesmas responsabilidades de cuidado e atenção para cada um deles ${ }^{25}$.

O sistema tributário projetado pelo autor poderia ser descrito da seguinte forma: imaginase o custo total do prêmio se todos na comunidade comprassem o mesmo nível de seguro; fixa-se tributos anuais agregados para fornecer uma soma igual ao prêmio de seguro hipotético; por hipótese, o prêmio produziria renda suficiente para que a comunidade pudesse então compensar aqueles com má sorte no valor que eles teriam direito se todos tivessem comprado o mesmo nível de seguro, compensação essa que poderia assumir a forma de transferências diretas ou gastos públicos para prover os benefícios. O autor considera o conceito econômico de "utilidade marginal decrescente" da renda, para afirmar que as pessoas com renda mais alta pagariam prêmios mais elevados (a

\footnotetext{
${ }^{21}$ MURPHY, NAGEL, op. cit nota 19. p. 43

${ }^{22}$ DWORKIN, Ronald. Is democracy possible here? principles foa a new debate. Princenton University Press: New Jarsey, 2006.

${ }^{23}$ DWORKIN, Ronald. Is democracy possible here? principles foa a new debate. Princenton University Press: New Jarsey, 2006.

${ }^{24}$ Idem.

${ }^{25}$ Ibidem.
}

Revista de Finanças Públicas, Tributação e Desenvolvimento, v. 6, n. 7, julho/dezembro, 2018, p. 100-121. 
porcentagem de sua renda em prêmios iria aumentar conforme a sua própria renda). Modelando a estrutura tributária hipotética na metáfora do seguro, portanto, o sistema de alíquotas seria progressivo e os regimes fiscais fixos ofenderiam o ideal de igualdade ex ante ${ }^{26}$.

Para Friedrich von Hayek, poucas medidas de política econômica que estão transformando a sociedade e produzindo resultados de grande projeção são tão firmemente estabelecidas e largamente aceitas, mesmo por pessoas que defendem a preservação de uma economia de livre mercado, como a redistribuição de renda através da tributação progressiva ${ }^{27}$.

A partir dessa concepção, pode-se extrair que o fundamento moral de justiça para a construção do sistema financeiro e tributário ideal é o redistributivo, com base na solidariedade social. Tendo em vista que um dos objetivos que se extrai para o Estado brasileiro é a construção de uma sociedade solidária, o objetivo de erradicar a pobreza e a marginalização não deve ser alcançado apenas pela ação positiva do Estado, mas depende de uma atuação solidária de cada cidadão ${ }^{28}$.

\subsection{A FUNÇÃO DOS TRIBUTOS NO ESTADO BRASILEIRO}

No que diz respeito ao fundamento dogmático, a sua busca se dá através de incursão no próprio ordenamento jurídico brasileiro, tendo por base os valores básicos adotados pela Constituição Federal de 1988. Para esta averiguação, deve-se ter em conta a crítica levantada por Ricardo Lobo Torres, acerca da segregação do Direito Tributário com o Direito Financeiro, o que causou e causa prejuízos no nosso desenvolvimento ${ }^{29}$.

O Direito Tributário não pode mais ser visualizado de forma segregada, apenas como um conjunto de direitos e garantias do contribuinte, como reflete, de certa forma, o Capítulo I do Título VI, da Constituição Federal, intitulado de "do Sistema Tributário Nacional”. É preciso situar efetivamente a tributação como instrumento para a aferição de receitas públicas, o que deve ser compreendido dentro da instrumentalidade da atividade financeira do Estado, direcionada para a promoção dos objetivos estatais (satisfação das necessidades públicas definidas pela Constituição).

\footnotetext{
${ }^{26}$ Ibidem. O autor ressalta ainda que um tributo regressivo, que exige que todos paguem o mesmo sobre suas compras seria obviamente ilegítimo. Aumentar, portanto, a parcela de tributação sobre o consumo gera a necessidade de cautela para manter o nível agregado de tributação tão alto quanto a progressividade hipotética exige.

${ }^{27}$ HAYEK, Friedrich August von. Reexaminando a taxação progressiva. In. FERRAZ, Roberto. Princípios e Limites da Tributácição, Quartier Latin: São Paulo, 2005. p.741-764.

${ }^{28}$ Ao tratar sobre a "virada kantiana", Ricardo Lobo Torres deixa claro que "[...] o problema do tributo passa também pelo crivo dos valores e o seu exame se faz sob a perspectiva da liberdade, da justiça, da igualdade e da solidariedade. A opção em torno da tributação é sempre valorativa". TORRES, Ricardo Lobo. Tratado de Direito Constitucional Financeiro e Tributário: Valores e princípios constitucionais tributários. Volume II. Rio de Janeiro: Renovar, 2014 .p. 55. ${ }^{29}$ Para Ricardo Lobo Torres, “[...] grande parte dos problemas das finanças públicas atuais, no Brasil e no estrangeiro, veio do corte observado entre poder de tributar e poder de gastar, ou entre Direito Tributário e Direito Financeiro, que conduziu à irresponsabilidade fiscal e à própria crise fiscal que desestruturou o Estado de Bem-Estar Social". TORRES, Ricardo Lobo. O Poder de Tributar no Estado Democrático de Direito. In: TÔRRES, Heleno Taveira (Coord.). Direito e Poder. Estudos em homenagem a Nelson Saldanha. São Paulo: Manole, 2005, p. 460-504.
} 
Dessa forma, a construção de um sistema tributário ideal deve concebê-lo como parte integrante do Direito Financeiro, dentro da dinâmica da atividade financeira do Estado, tendo por objetivos fundamentais:

“[...] construir uma sociedade livre, justa e solidária; garantir o desenvolvimento nacional; erradicar a pobreza e a marginalização e reduzir as desigualdades sociais e regionais; e promover o bem de todos, sem preconceitos de origem, raça, sexo, cor idade e quaisquer outras formas de discriminação" (art. $3^{\circ}$ da Constituição Federal).

Para Marco Aurélio Greco, a indicação de objetivos "não é mera declaração de boas intenções", mas condicionante para mecanismos e instrumentos criados no exercício das competências constitucionais ${ }^{30}$.

Marciano Godoi explica que tal objetivo leva a duas posturas: a menos exigente responde que uma sociedade solidária é aquela que reconhece, valoriza e incentiva que seus cidadãos pratiquem atos solidários; a postura mais exigente entende que uma sociedade solidária é aquela que se ergue sobre os pilares de sustentação efetivamente solidários. $\mathrm{O}$ autor se posiciona pela postura mais exigente, por entender que "[...] se os pilares de sustentação de uma sociedade descuidam por completo da solidariedade entre os cidadãos, não serão práticas ou ações solidárias mais ou menos isoladas ou mais ou menos episódicas que tornarão essa sociedade verdadeiramente solidária"31.

Assim, como bem ressalta Ricardo Lobo Torres, “[...] o dispositivo deve ser entendido como norma programática e exortativa para o trabalho do legislador e não como declaração de princípios jurídicos" 32 . O art. $3^{\text {o }}$ da Constituição, portanto, deve ser concebido como pauta de realização para o Estado.

Ou seja, a assunção da responsabilidade pela construção de uma sociedade solidária não deve ser vista apenas do ponto de vista dos cidadãos diante dos seus semelhantes, mas também do ângulo do Estado para a sociedade ${ }^{33}$. Marco Aurélio Greco vai além e afirma que o estabelecimento de um objetivo fundamental faz com que todos os instrumentos e categorias existentes devem ser utilizados e concebidos em sua direção ${ }^{34}$.

A partir da identificação dos objetivos fundamentais para os quais o Estado está direcionado, a proposta de um sistema financeiro e tributário deve ter como ponto de partida (e de chegada) o alcance desses objetivos.

\footnotetext{
${ }^{30}$ GRECO, Marco Aurélio. Solidariedade social e tributação. In: GRECO, Marco Aurélio; GODOI, Marciano Seabra de (Orgs.). Solidariedade social e tributação. São Paulo: Dialética, 2005, p. 168-189. p. 172.

${ }^{31}$ GRECO, Marco Aurélio. Solidariedade social e tributação. In: GRECO, Marco Aurélio; GODOI, Marciano Seabra de (Orgs.). Solidariedade social e tributação. São Paulo: Dialética, 2005, p. 168-189, p. 148.

32 TORRES, Ricardo Lobo. Tratado de Direito Constitucional Financeiro e Tributário: Valores e princípios constitucionais tributários. Volume II. Rio de Janeiro: Renovar, 2014. p. 48.

${ }^{33}$ GRECO, op. cit. nota 29. p. 173.

${ }^{34}$ Ibidem. p. 175 .
} 
Tendo, portanto, como parâmetro a Constituição Federal de 1988, pode-se chegar à mesma conclusão que Francesco Moschetti chegou a respeito da Constituição Italiana: o dever de todos de concorrer com os gastos públicos em virtude de suas capacidades contributivas é expressão do dever de solidariedade econômica, política e social ${ }^{35}$.

Ernani Contipelli reforça ainda que a proposta da solidariedade social em torno de um ambiente de cooperação recíproca marcado pela ideia de dignidade social leva à "[...] participação financeira do membro da comunidade na efetivação do programa de ação constitucional destinado ao atendimento do bem comum com o cumprimento de seu dever de colaboração de pagar tributo"36.

O Sistema Tributário, assim, deixa de ser mero instrumento de geração de recursos para o Estado, para ser verdadeiro instrumento para a realização dos seus objetivos fundamentais ${ }^{37}$. Adota um lugar central no Estado Democrático de Direito, como seu pressuposto funcional, tendo como fundamento a noção de que a tributação tem também como sentido "cumprir com o caráter solidário e redistributivo via arrecadação ${ }^{38}$.

Nabais destaca essa função dos impostos como extrafiscal (em contraposição à função físcal, ou seja, mera arrecadação de recursos), reconhecendo ser não apenas admissível, mas constitucionalmente exigível, como decorrência da modelação econômico-social em que o estado social se materializa, não podendo o Estado dispensar o seu mais importante instrumento (os impostos) $)^{39}$.

Construir uma sociedade solidária, entretanto, não deve ser apenas um objetivo extrafiscal da tributação, mas o cerne da sua existência, adotando feições propriamente fiscais.

A solidariedade, como critério norteador da construção do Estado e, portanto, do Sistema Tributário Nacional, levará a uma concepção própria de capacidade contributiva como critério de justiça fiscal ${ }^{40}$.

\footnotetext{
${ }^{35}$ MOSCHETTI, Francesco. El Principio De La Capacidad Contributiva. In: AMATUCCI, Andrea (Org.). Tratado de Derecho Tributario, 2001, v. I, p. 241-242.

${ }^{36}$ CONTIPELLI, Ernani. Solidariedade social tributária. São Paulo: Almedina, 2010. p. 221.

${ }^{37}$ GRECO, Marco Aurélio. Solidariedade social e tributação. In: GRECO, Marco Aurélio; GODOI, Marciano Seabra de (Orgs.). Solidariedade social e tributação. São Paulo: Dialética, 2005, p. 168-189. p. 177.

38 BUFFON, Marciano; MATOS, Mateus Bassani de. Tributação no Brasil do século XXI: uma abordagem hermeneuticamente crítica. Porto Alegre: Livraria do Advogado, 2015. p. 145.

${ }^{39}$ NABAIS, José Casalta. O dever fundamental de pagar impostos: contributo para a compreensão constitucional do estado fiscal contemporâneo. Coimbra: Almedina, 2015. P. 244. Para Nabais, "[...] a função econômica e a função fisscal dos impostos em rigor não se apresentam contrapostas nem separadas, mas sim imbricadas numa relação de recíproca dependência. (...) [...] a função econômica da tributação prima facie extrafiscal tenha assim caráter fiscal" (p. 234).

${ }^{40}$ Para Francesco Moschetti, "solidariedade e capacidade contributiva são dois aspectos da mesma realidade": de um lado, a solidariedade requer o critério de repartição conforme a capacidade contributiva; de outro, a assunção da capacidade contributiva como fundamento para repartição dos tributos indica uma visão da relação entre cidadãos e sociedade que não se baseia no individualismo, mas numa síntese dos ideais de liberdade e socialidade que é própria do solidarismo (tradução livre). MOSCHETTI, Francesco. El Principio De La Capacidad Contributiva. In: AMATUCCI, Andrea (Org.). Tratado de Derecho Tributario, 2001, v. I, p. 243.
} 
Afirmar íntimas relações entre solidariedade e tributo e o reconhecimento da existência de um dever fundamental de pagar impostos ainda pode ser mal compreendido pelos brasileiros. Marciano Godoi explica as possíveis razões para isso: tradição positivista hegemônica na doutrina do Direito Tributário das últimas décadas; longo período de autoritarismo que se seguiu ao golpe de 1964; excessiva postura garantista oferecida pelo Direito Tributário; reduzida abertura da maioria da doutrina a contatos e investigações da doutrina e jurisprudência estrangeiras ${ }^{41}$.

Por outro lado, pode-se vislumbrar que a função dos tributos está tão intimamente ligada aos objetivos fundamentais que a demanda pela construção de uma sociedade livre, justa e solidária encontra-se em consonância, neste aspecto, com a demanda pelo desenvolvimento.

De acordo com Galledo Peragón, os Estados menos desenvolvidos têm a ideia de que a tributação progressiva é uma das ideias centrais para o desenvolvimento, que esse tipo de sistema tributário é indicativo de país civilizado, reconhecendo que a igualdade não se alcança apenas com o simples funcionamento das forças econômicas e sociais ${ }^{42}$. Ou seja, espelhar-se em modelos tributários adotados pelos países desenvolvidos significa adotar um sistema tributário progressivo, o que também corrobora com a realização dos demais objetivos fundamentais.

Investigar a função dos tributos no Estado brasileiro leva, portanto, à constatação da íntima relação entre tributação e solidariedade e faz com que a progressividade seja elevada de uma simples técnica de definição de alíquotas para alguns impostos específicos, para uma ideia diretriz de todo o sistema.

\subsection{A PROGRESSIVIDADE COMO PRINCÍPIO GERAL IMPLÍCITO NO SISTEMA TRIBUTÁRIO NACIONAL}

Após estabelecer os delineamentos da progressividade como regra e como princípio, verifica-se que há uma evidente distinção entre o caráter progressivo de um imposto particular e o caráter progressivo da carga de todo um sistema tributário ${ }^{43}$.

Mesmo garantindo a tributação progressiva da renda, uma tributação indireta sobre as rendas mais baixas pode tornar o sistema, como um todo, regressivo, como acontece no Brasil. Neste caso, pode ser que a regra da progressividade do imposto sobre a renda esteja sendo atendida, a

\footnotetext{
${ }^{41}$ GODOI, Marciano Seabra de. Tributo e Solidariedade Social. In: GRECO, Marco Aurélio; GODOI, Marciano Seabra de. (Org.). Solidariedade Social e Tributação. São Paulo: Dialética, 2005, p. 158.

${ }^{42}$ GALLEDO PERAGÓN, José Manuel. Los principios materiales de justicia tributaria. Granada, 2003. p. 161.

${ }^{43}$ HAYEK, Friedrich August von. Reexaminando a taxação progressiva. In. FERRAZ, Roberto. Princípios e Limites da Tributação, Quartier Latin: São Paulo, 2005. p.746.
} 
despeito do distanciamento considerável do sistema à realização da progressividade como princípio, o que vem ofendendo, inclusive, o princípio da capacidade contributiva ${ }^{44}$.

A partir do ideal de solidariedade e de redistribuição, extrai-se do sistema jurídico brasileiro que o sistema financeiro e tributário ideal deve ser progressivo. A tributação progressiva, conforme demonstrou Piketty, a partir de uma pesquisa empírica e histórica de suma importância para o início do séc. XXI, desempenhou papel fundamental no desenvolvimento do Estado social e na transformação na da estrutura da desigualdade no séc. XX, nos países considerados mais desenvolvidos ${ }^{45}$.

Essa progressividade não deve ser extraída de alguns tributos específicos, como os impostos sobre a renda e o patrimônio, conforme previsão expressa da nossa Constituição, mas deve ser uma progressividade sistêmica, de forma que, na análise final da incidência da carga tributária, o critério de sua repartição seja progressivo e que o sistema tributário, dentro do financeiro, seja capaz de se adequar aos objetivos fundamentais da República Federativa do Brasil, principalmente no que diz respeito à construção de uma sociedade justa, livre e solidária ${ }^{46}$.

A progressividade, como princípio, mesmo que não prevista expressamente na Constituição Federal, deve ser adotada como decorrência lógica do princípio do estado social, como "suporte de justiça social”, este sim expressamente previsto ${ }^{47}$.

Somente através da progressividade sistêmica, como decorrência dos critérios de justiça adotados pela Constituição, alcança-se a igualdade sistemática, tornando a atividade legislativa coerente com suas próprias decisões fundamentais ${ }^{48}$.

\footnotetext{
44 "O princípio jurídico da capacidade contributiva resume o essencial sobre a ideia de justiça liberal, pois autoriza o Estado a cobrar de cada contribuinte um ônus compatível com sua situação econômica, tendendo a atingir em maior grau aqueles que possuem mais receita. A eficácia da justiça materializa-se na seletividade da tributação dos bens e na progressividade das alíquotas que gravam a renda e o patrimônio". PALMEIRA, Marcos Rogerio. Direito Tributário versus Mercado: o liberalismo na reforma do estado brasileiro nos anos 90. Rio de Janeiro: Renovar, 2002. p.76.

${ }^{45}$ PIKETTY, Thomas. O Capital no século XXI. Trad. Monica Baumgarten De Bolle. Rio de Janeiro: Intrínseca, 2014. p. 484.

${ }^{46}$ Para Marciano Godoi, o mínimo que se espera de um sistema tributário globalmente considerado é que responda às exigências de capacidade econômica, ou seja, que seja inspirado em critérios de progressividade. GODOI, Marciano Seabra de. Tributo e Solidariedade Social. In: GRECO, Marco Aurélio; GODOI, Marciano Seabra de. (Org.). Solidariedade Social e Tributação. São Paulo: Dialética, 2005, p. 160.

${ }^{47}$ Nabais chega a esta mesma conclusão, em relação à Constituição Portuguesa, mas faz 2 observações: a primeira é que, para este autor, a progressividade não é a única via nem a via necessária para a justiça social (ele defende a eficiência de sobrecarregar os rendimentos mais altos e os patrimônios maiores, o que não deixa de ser uma certa progressividade na concepção adotada neste trabalho); outra observação é que, apesar de a progressividade na receita não gerar necessariamente reversão desse incremento para gastos direcionados àqueles que ganham menos, não torna legítima a conclusão de que a progressividade dos impostos não tem justificação no princípio do estado social, refutando, assim, um argumento recorrente contra a progressividade. NABAIS, José Casalta. O dever fundamental de pagar impostos: contributo para a compreensão constitucional do estado fiscal contemporâneo. Coimbra: Almedina, 2015. p. 577-578.

${ }^{48}$ Humberto Ávila destaca o dever do legislador de respeitar as suas próprias decisões fundamentais, ou seja, respeitar os princípios básicos que ele mesmo adotou, levando-os de modo coerente, inclusive dentro de um mesmo corpo normativo. Trata-se do dever de evitar contradições internas, que o autor nomeia de dever de igualdade sistêmica (p. 128), ou "dever de congruência sistemática”. ÁVILA, Humberto. Teoria da Igualdade Tributária. São Paulo: Malheiros, 2009. p. 129.
} 
É preciso ressaltar que, apesar de tais critérios poderem ser extraídos do sistema jurídico, como fundamentos para construção do sistema tributário ideal, para integrá-lo ao sistema financeiro e, efetivamente, alcançar os objetivos estatais fundamentais, a exigência de tributação justa não pode se distanciar da justiça na realização dos gastos públicos.

$\mathrm{Na}$ concepção de um sistema tributário e financeiro ideal, não apenas a tributação deve ser redistributiva, através da progressividade. Os gastos públicos devem ser redistributivos, em essência, sob pena de responsabilidade na gestão fiscal. As prioridades no gasto público, portanto, devem ser definidas, de maneira eficiente, de forma a priorizar as despesas redistributivas, no bojo do desenvolvimento social e econômico, sem se distanciar das garantias de liberdade do cidadão. Mas, quando se fala em liberdade aqui, trata-se de igual liberdade para todos, o que pode ser alcançado por meio de critérios justos de tributação redistributiva somados à responsabilidade do gasto público direcionado, prioritariamente, para programas redistributivos.

No entanto, conforme se verificará adiante, para o caso específico do Estado Brasileiro, a adoção do princípio geral da progressividade para a definição do sistema tributário é uma medida que, por si só, já realiza os seus objetivos fundamentais. Ao contrário do que se defende numa posição mais pessimista da realidade ${ }^{49}$, a progressividade dos gastos não é condição para que a progressividade na arrecadação cumpra seu papel. Ambas as medidas somadas representam o ideal, mas a pendência de uma não impede a adoção da outra.

A partir desses parâmetros, é preciso ressaltar que a construção de um sistema tributário progressivo deve trazer influências nas previsões constitucionais das competências tributárias e, portanto, todas as considerações sobre a manutenção da autonomia financeira dos entes federativos devem ser realizadas, a fim de atender a um federalismo fiscal equilibrado e de cooperação, também compatível com o alcance dos objetivos fundamentais.

Deve-se observar, no entanto, que a busca pela realização do princípio da progressividade encontra limites nos direitos fundamentais do contribuinte, não podendo alcançar um grau tal que assuma um caráter confiscatório, violando, assim, o núcleo do direito fundamental à propriedade e à livre iniciativa.

\footnotetext{
${ }^{49}$ Para exemplificar tal posicionamento, defendido por muitos representantes da doutrina do direito tributário, verifica-se a posição de Friedrich August von Hayek, que, no contexto de sua representação à Escola Austríaca e da análise de dados dos Estados Unidos e Reino Unido, entende que a defesa da progressividade é uma falácia, porque a carga que atinge as camadas mais pobres é compensada pelos efeitos redistributivos do gasto do Governo. Esta compensação, entretanto, sequer é verifica no contexto brasileiro. HAYEK, Friedrich August von. Reexaminando a taxação progressiva. In. FERRAZ, Roberto. Princípios e Limites da Tributação, Quartier Latin: São Paulo, 2005. p. 744. A concepção do autor, portanto, acaba reforçando o argumento construído no presente trabalho de que a progressividade deve ser sistêmica, ou seja, todos os fatores da tributação devem ser considerados.
} 
Ressalta-se que esse não é o único modelo redistributivo que o Estado pode $\operatorname{adotar}^{50}$. Entretanto, se se quer construir um sistema tributário em consonância com os valores constitucionais básicos, é necessário que este cumpra com os objetivos fundamentais previstos pela Constituição e, neste caso, o melhor modelo seria o da tributação progressiva.

\section{OS EFEITOS DE SE CONCEBER A PROGRESSIVIDADE TAMBÉM COMO UM PRINCÍPIO GERAL E SUA VIOLAÇÃO PELO SISTEMA TRIBUTÁRIO ATUAL}

A partir da conclusão de que a progressividade é um princípio geral e implícito que pode se extrair do Sistema Tributário Nacional, este tópico será dedicado a verificar a relevância dessa investigação, em termos de indicar os efeitos práticos esperados pela adoção da progressividade como um princípio, além de confrontar esse objetivo com a realidade atual da distribuição da carga tributária no Brasil.

\subsection{OS EFEITOS PRÁTICOS ESPERADOS PELA ADOÇÃO DA PROGRESSIVIDADE COMO UM PRINCÍPIO GERAL DO SISTEMA TRIBUTÁRIO NACIONAL}

A mudança de paradigma a respeito da progressividade é verificada, atualmente, com a própria mudança de posicionamento do STF a seu respeito. Pode-se dizer, em suma, que este Tribunal vem somando à ideia de que a progressividade é uma regra (uma técnica de definição das alíquotas de alguns impostos) a adoção da progressividade como princípio.

O posicionamento originário pode ser identificado no RE 153.771-MG, em que se declarou a inconstitucionalidade o IPTU progressivo, antes da Emenda Constitucional 29/2000, basicamente pela falta de previsão expressa na Constituição (art. 145, §1 $1^{\circ}$, art. $156, \S 1^{\circ}$ e $182, \S \S 2^{\circ}$ e $4^{\mathrm{o}}$, II) e por ser o IPTU um imposto de caráter real. O IPTU só poderia ser progressivo para assegurar o cumprimento da função social da propriedade. Apesar da divergência na decisão, esse

\footnotetext{
${ }^{50}$ Para Freidrich Hayek, “[...] é claro que a tributação progressiva não é o único método através do qual uma redistribuição de rendas pode ser realizada. Seria possível efetuar uma considerável redistribuição num sistema de tributação proporcional. Para consegui-lo bastaria devotar uma parte substancial da renda do imposto ao financiamento de serviços que beneficiem principalmente os relativamente pobres - ou subsidiá-los diretamente". No entanto, o próprio autor verifica que a tributação proporcional não geraria o achatamento do topo das rendas e faria com que os próprios pobres financiassem, através de tributos, serviços gratuitos que usufruiriam do Estado. Assim, o autor assume que "[...] parece inquestionável que a tributação progressiva seja a principal ferramenta disponível para realizar uma redistribuição de renda e que sem esta o alcance de uma tal política seria muito limitado". HAYEK, Friedrich August von. Reexaminando a taxação progressiva. In. FERRAZ, Roberto. Princípios e Limites da Tributação, Quartier Latin: São Paulo, 2005. p. 745 .
}

Revista de Finanças Públicas, Tributação e Desenvolvimento, v. 6, n. 7, julho/dezembro, 2018, p. 100-121. 
posicionamento só foi modificado com a introdução pela Emenda Constitucional 29/2000 da previsão expressa de que o IPTU será progressivo em razão do valor do imóvel (art. 156, $\left.\S 1^{\circ}, \mathrm{I}\right)^{51}$.

Outra referencia ao posicionamento superado é o RE 234.105-SP, em que o STF, por unanimidade, decidiu pela inconstitucionalidade do ITBI progressivo, por inexistência de autorização constitucional, realizando a capacidade contributiva com base na proporcionalidade.

Alberto Macedo analisa a "virada na jurisprudência” através do RE 562/045-RS, em que o STF, apenas em 2013, adota a constitucionalidade do ITCMD progressivo, com base no princípio da capacidade contributiva, não obstante a inexistência de qualquer previsão constitucional nesse sentido ${ }^{52}$.

O STF, portanto, apesar de não denominar a progressividade expressamente como princípio, adotou-o para dar concreção ao princípio da capacidade contributiva, que demanda um tratamento pessoal e, portanto, progressivo, nos impostos sobre a propriedade ${ }^{53}$.

De todo modo, esse é um efeito da mudança de paradigma, mas um efeito bem tímido, diante do que se revela no contexto geral para o Sistema Tributário Nacional.

O primeiro efeito de se conceber a progressividade como um princípio geral, portanto, é a recomendação para se estabelecer alíquotas progressivas em outros impostos que não apenas o incidente sobre a renda, como sobre os impostos incidentes sobre patrimônio, herança e doação. Podese dizer que o primeiro passo está sendo dado no âmbito da interpretação.

O segundo passo consiste na análise da progressividade não das alíquotas de impostos isolados, mas da consideração do conjunto dos impostos incidentes sobre determinado rendimento (ou faixa de renda, numa análise global). Recomenda-se, ainda, que, dentro desta análise global, a progressividade da tributação do patrimônio leve em consideração a distribuição patrimonial nacional e não apenas a base de cálculo de cada imposto, além de ser baseada em avaliações patrimoniais constantemente atualizadas.

A partir daí é preciso fazer com que a inevitável regressividade gerada por alíquotas proporcionais de alguns tributos (como os chamados indiretos ou incidentes sobre o consumo) seja compensada pela efetiva progressividade de outros (diretos ou incidentes sobre a riqueza - renda e patrimônio), para que, globalmente, a carga seja distribuída de forma verdadeiramente progressiva.

\footnotetext{
${ }^{51}$ MACEDO, Alberto. A progressividade fiscal nos impostos sobre a propriedade e a decisão do STF sobre o ITCMD. In: PARISI, Fernanda Drummond; TÔRRES, Heleno Taveira; MELO, José Eduardo Soares de (Org.). Estudos de Direito Tributário em homenagem ao Professor Roque Antonio Carraza. São Paulo: Malheiros, 2014, v. 2, p. $269-292$.

52 Idem, p. 269-292.

${ }^{53}$ O STF reconheceu que “[...] A função essencial da progressividade consiste em dar concreção ao princípio da capacidade contributiva de modo a promover a justice social em material tributária, servindo como importante instrumento de desconcentração de riqueza. BRASIL. Supremo Tribunal Federal. Recurso Extraordinário no 562.045-RS. Recorrentes: Estado do Rio Grande do Sul. Recorrido: Espólio de Emília Lopes de Leon. Relator: Min. Ricardo Lewandowski. Brasília, $\quad 06 / 02 / 2013 . \quad$ Disponível em http://redir.stf.jus.br/paginadorpub/paginador.jsp?docTP=AC\&docID=630039 . Acesso em: 26 set. 2017.
} 
Outro passo de suma importância diz respeito à ampliação da base tributária ${ }^{54}$, através da redução de benefícios fiscais indiscriminados, que não estejam em consonância com a realização da progressividade global. Os benefícios devem se concentrar no consumo de bens de primeira necessidade, renda mínima e, apenas como último recurso e por tempo estritamente determinado, como medida extrafiscal de estímulo econômico.

Tais passos são efeitos lógicos de se conceber a progressividade como princípio geral norteador do Sistema Tributário Nacional e se configuram como ponto de partida para uma complexa reforma do próprio sistema, para que ele seja enquadrado no âmbito dos objetivos fundamentais do Estado Democrático de Direito.

\subsection{A PROGRESSIVIDADE COMO PRINCÍPIO NO ÂMBITO DA SITUAÇÃO ATUAL DA DISTRIBUIÇÃO DAS CARGAS NO SISTEMA TRIBUTÁRIO BRASILEIRO}

A situação do Sistema Tributário Brasileiro permanece na contramão dos ideais de justiça, dos objetivos fundamentais do Estado e do próprio fundamento moral e jurídico para a tributação.

Em 2017, a Oxfam Brasil publicou um trabalho sob o título "A distância que nos une: um retrato das desigualdades brasileiras" ${ }^{" 55}$. No tópico sobre os caminhos e descaminhos na redução de desigualdades, ela analisou que os "super-ricos" no Brasil pagam pouco imposto sobre a renda e proventos de qualquer natureza e analisou ainda a distribuição da carga entre tributos diretos e indiretos, para avaliar a influência da tributação nas desigualdades sociais.

A carga tributária, no Brasil, é mal distribuída, fazendo com que as pessoas que se encontram nas faixas de rendas mais baixas paguem proporcionalmente mais tributos do que as pessoas que se encontram nas faixas mais altas de renda. Isso se deve por vários fatores, entre eles: “perda da progressividade nas faixas de renda mais altas do imposto de renda, má distribuição da carga entre impostos diretos e indiretos, baixa tributação do patrimônio e elisão e evasão fiscal"56.

O primeiro dado encontrado pela Oxfam foi o de que “[...] pessoas que ganham 320 salários mínimos mensais pagam uma alíquota efetiva de imposto [...] similar à de quem ganha cinco

\footnotetext{
54 “O estreitamento da base tributária se dá quando governos sucessivos introduzem concessões tributárias que divergem de qualquer definição moral de renda, e essas "cracas" que grudam no casco do navio fiscal se mostram notavelmente pegajosas. Essas concessões normalmente consistem em 'gastos tributários' que são equivalentes, em termos orçamentários, a despesas de capital”. ATKINSON, Anthony B. Desigualdade: o que pode ser feito? Trad. Elisa Câmara. São Paulo: Leya, 2015. p. 231.

55 OXFAM BRASIL. A distância que nos une: um retrato das desigualdades brasileiras. Disponível em: < https://www.oxfam.org.br/sites/default/files/arquivos/Relatorio_A_distancia_que_nos_une.pdf $>$. Acesso em: 26 set. 2017.

56 OXFAM BRASIL. A distância que nos une: um retrato das desigualdades brasileiras. Disponível em: < https://www.oxfam.org.br/sites/default/files/arquivos/Relatorio_A_distancia_que_nos_une.pdf >. Acesso em: 26 set. 2017.
}

Revista de Finanças Públicas, Tributação e Desenvolvimento, v. 6, n. 7, julho/dezembro, 2018, p. 100-121. 
salários mínimos mensais, e quatro vezes menos em comparação com declarantes de rendimentos mensais de 15 a 40 salários mínimos" ${ }^{" 57}$. Verifica-se, portanto, que, no âmbito do próprio imposto de renda, em que a progressividade é uma regra específica, a progressividade falha, diante da realidade de distribuição de rendas do país. Ela só é verificada até a faixa dos 20 a 40 salários mínimos de rendimento, caindo, justamente nos grupos mais ricos do país.

Quanto à tributação do patrimônio, verifica-se também que a análise da distribuição da carga tributária em relação à distribuição do usufruto dos bens imobiliários residenciais e ao rendimento das famílias apresenta uma estrutura altamente regressiva entre os contribuintes de fato do imposto. Isso se deve a proporção entre os pagantes e não pagantes, além de uma falha no processo de avaliação imobiliária (que, geralmente, agrava mais as pessoas que se encontram nas faixas de renda mais baixas) ${ }^{58}$.

Muitas pesquisas apontam também para a regressividade gerada a partir do peso que se dá à tributação do consumo. A Oxfam, que utiliza dados de 2015 , verificou que $53 \%$ da receita tributária do Brasil é formada por tributação do consumo ${ }^{59}$. Note-se que a tributação do consumo não é sequer proporcional.

O Conselho de Desenvolvimento Econômico e Social, em 2011, já havia apresentado o $2^{\circ}$ Relatório de observações sobre os indicadores de equidade no Sistema Tributário Nacional ${ }^{60}$. De acordo com o relato, em 2004, no Brasil, “[...] quem ganhava até dois salários mínimos gastava 48,8\% de sua renda no pagamento de tributos, já o peso da carga tributária para as famílias com renda superior a 30 salários mínimos correspondia a 26,3\%"61. Tal percentual se reduz na medida em que a renda aumenta.

A influência dos tributos sobre o consumo (os chamados indiretos) nesta gradação é evidente. Quando se decompõe a carga tributária total sobre a renda familiar em ônus tributário direto e ônus tributário indireto, verifica-se que a gradação não se justifica, em termos de justiça fiscal. O ônus da tributação direta sobre quem ganhava até dois salários mínimos era de 3,1\%, já sobre quem ganhava mais de 30 salários mínimos era de 9,9\%. Por outro lado, o ônus da tributação indireta sobre

\footnotetext{
57 OXFAM BRASIL. A distância que nos une: um retrato das desigualdades brasileiras. Disponível em: < https://www.oxfam.org.br/sites/default/files/arquivos/Relatorio_A_distancia_que_nos_une.pdf >. Acesso em: 26 set. 2017.

${ }^{58}$ Essa constatação advém de um estudo publicado pelo IPEA em 2009. Carvalho Jr., Pedro Humberto Bruno de. Aspectos distributivos do IPTU e do patrimônio imobiliário das famílias brasileiras. Rio de Janeiro: IPEA, 2009.

${ }^{59}$ OXFAM BRASIL. op. cit. nota 55.

${ }^{60}$ CONSELHO DE DESENVOLVIMENTO ECONÔMICO E SOCIAL. Indicadores de iniquidade do Sistema Tributário Nacional - Relatório de Observação n $n^{\mathrm{o}}$ 2. $2^{\mathrm{a}}$ ed. Brasília, 2011.

${ }^{61}$ Idem.
}

Revista de Finanças Públicas, Tributação e Desenvolvimento, v. 6, n. 7, julho/dezembro, 2018, p. 100-121. 
quem ganhava até dois salários mínimos era de 45,8\%, enquanto quem ganhava acima de trinta salários mínimos sofria o ônus de apenas $16,4 \%{ }^{62}$.

A Oxfam verificou, ainda, que o panorama da distribuição da carga tributária brasileira penaliza, ainda mais, aos negros e mulheres, por um reflexo da realidade social: "três em cada quatro brasileiros que estão na faixa dos $10 \%$ mais pobres - a que gasta mais tributos - são negros e mais da metade são mulheres. Por outro lado, entre os $10 \%$ mais ricos, os que pagam a menor quantidade relativa a impostos, dois em cada três são brancos e são homens"63.

Comparado aos demais países da OCDE, o Brasil é o país que possui a maior carga tributária sobre bens e serviços $(17,9 \%$ do PIB nacional $)$ - muito acima da média da OCDE $(11,5 \%)$ e o penúltimo na gradação da carga tributária sobre a renda, lucro de ganho de capital $(6,1 \%$ do PIB nacional), sendo maior apenas que a Turquia (5,9\% do PIB nacional) - muito abaixo da média dos países OCDE (11,7\%). A carga tributária sobre a folha de salários (8,5\% do PIB nacional) está um pouco abaixo da média da OCDE $(9,6 \%)$, o que também acontece com a carga sobre a propriedade $(1,3 \% \text { no Brasil, abaixo de } 1,9 \% \text { - média da OCDE })^{64}$.

Somado a tudo isso, há ainda a reunião de dados pela Oxfam de que a sonegação tributária chegou a ordem de R $\$ 275$ bilhões em 2016 e, neste mesmo ano, a estimativa de renúncias de receitas fiscais alcançaram R $\$ 271$ bilhões $^{65}$, o que distorce, ainda mais, o panorama da distribuição das cargas tributárias.

Com esses dados, podemos concluir que o Sistema Tributário Brasileiro é regressivo, fazendo com que as camadas mais pobres tenham uma participação proporcionalmente maior no financiamento do Estado.

Em razão da situação demonstrada, refuta-se, de antemão, o argumento de que não adianta promover a progressividade da tributação sem a progressividade dos gastos públicos. É evidente que o ideal para o cumprimento dos objetivos fundamentais é, de fato, promover a progressividade tanto nos ingressos quanto nos gastos públicos. No entanto, diante do suporte fático para o qual a norma tributária se direciona, verifica-se que o Sistema Tributário Brasileiro, hoje, corrobora com a situação de desigualdade e injustiça com a simples sistemática de arrecadação, dirigindo-se na contramão de qualquer valor concernente ao Estado Democrático de Direito.

\footnotetext{
${ }^{62}$ CONSELHO DE DESENVOLVIMENTO ECONÔMICO E SOCIAL. Indicadores de iniquidade do Sistema Tributário Nacional - Relatório de Observação n ${ }^{\circ}$ 2. $2^{\mathrm{a}}$ ed. Brasília, 2011.

63 OXFAM BRASIL. A distância que nos une: um retrato das desigualdades brasileiras. Disponível em: < https://www.oxfam.org.br/sites/default/files/arquivos/Relatorio_A_distancia_que nos_une.pdf >. Acesso em: 26 set. 2017.

64 RECEITA FEDERAL. Carga tributária no Brasil 2014. Disponível em: http://idg.receita.fazenda.gov.br/dados/receitadata/estudos-e-tributarios-e-aduaneiros/estudos-e-estatisticas/cargatributaria-no-brasil/29-10-2015-carga-tributaria-2014. Acesso em: 8 jul. 2016.

${ }^{65}$ OXFAM BRASIL. op. cit. nota 62.
} 
A injustiça do Sistema Tributário gera, por consequência lógica, a injustiça na distribuição de direitos na sociedade, que é resultante do regime tributário adotado ${ }^{66}$. Isso afeta diretamente o Estado Democrático de Direito, diante da distribuição invertida de ônus sociais entre os membros da sociedade. Isso, por si só, já consiste em um problema, que é agravado pela consequente má distribuição de direitos (que envolve também os gastos).

A adoção da progressividade geral do Sistema Tributário, por si só, já é um instrumento valioso e eficiente para a realização dos princípios constitucionais fundamentais em grau muito maior do que o que se vislumbra atualmente. Reformar o Sistema Tributário para torna-lo progressivo é uma medida imprescindível e urgente, ainda que não haja qualquer reformulação na sistemática dos gastos públicos (o que se constitui medida também necessária, mas não condicionante ou pressuposta), como medida pela sobrevivência do Estado Democrático de Direito.

\section{CONCLUSÃO}

A justa distribuição da carga tributária deve ser encontrada, a partir da concepção de tributo como receita pública, que viabiliza, através da atividade financeira do Estado (instrumento), a realização dos objetivos fundamentais da República Federativa do Brasil (art. $3^{\circ}$ da CF). Deve, portanto, ser norteado pelos princípios da justiça, igualdade, liberdade e, sobretudo, solidariedade.

A partir da identificação dos ideais liberais com tendências igualitárias da Constituição, o Sistema Financeiro e Tributário ideal deve ter como parâmetro a justiça fiscal redistributiva, principalmente visando o equilíbrio entre igualdade e liberdade, tendo em conta principalmente a ideia de igual liberdade.

Assim, para construção da sociedade livre e justa, a distribuição da carga tributária deve ser progressiva (progressividade sistêmica), com fins redistributivos, o que norteará também a política de gastos públicos, para manutenção da coerência do sistema e alcance dos objetivos fundamentais.

A progressividade, portanto, não deve ser vista apenas como uma regra jurídica a nortear a definição da alíquota de alguns tributos específicos (IR, IPTU e ITR), como foi expressamente contemplada na Constituição Federal de 1988.

A progressividade deve ser concebida também como um princípio jurídico, um ideal a ser perseguido pelo sistema jurídico tributário como um todo, como resultado lógico do propósito primeiro de existência dos próprios tributos no contexto constitucional brasileiro.

Como princípio, deve nortear a construção do Sistema Tributário Nacional para uma situação ideal de redução das desigualdades econômicas e até de redistribuição de riquezas, sob o

\footnotetext{
${ }^{66}$ MURPHY, Liam; NAGEL, Thomas. O Mito da Propriedade. São Paulo: Martins Fontes, 2015. p. 11.
} 
manto do princípio da solidariedade. Assim, a distribuição da carga tributária como um todo, considerando todos os tributos (diretos e indiretos), por faixa de renda, deve se dar de forma progressiva.

A tributação no Brasil presta um desserviço aos seus objetivos fundamentais. A solução pratica do problema não reside em trazer à Constituição a previsão expressa do princípio da progressividade, mas reconhecê-lo e modificar as normas tributárias de modo a realizá-lo na maior medida possível.

Ressalte-se, ainda, que também não refuta o princípio o argumento de que seria impossível a progressividade plena do sistema sem que a tributação se tornasse confiscatória no topo das faixas de renda. Sendo um princípio geral do sistema, deve ser realizado na maior medida possível dentro das condições fáticas e jurídicas.

Além disso, o contexto fático demonstra que a adoção da progressividade na distribuição da carga tributária, por si só, já é medida eficaz na empreitada para a construção de uma sociedade livre, justa e solidária. Apesar de a reforma nos gastos públicos ser também urgente e completar a engenharia proposta, não é medida condicionante à progressividade na tributação.

Hoje, o que se verifica é uma constante violação ao princípio, pois, no âmbito das condições fáticas e jurídicas, ele não tem a sua capacidade máxima (sequer mínima) de aplicação verificada.

Qualquer projeto de reforma tributária deve levar em consideração a progressividade como um princípio geral implícito do Sistema Tributário Nacional, pois, sem perder de vista a resolução dos problemas fiscais federativos, a revisão da carga tributária por faixa de renda, para tornar a distribuição do ônus progressiva tornou-se uma medida urgente, sob fundamentos tanto dogmáticos quanto morais. Somente com o reconhecimento desse princípio será possível construir uma sociedade livre, justa e solidária.

\section{REFERÊNCIAS}

ALEXY, Robert. Teoria dos Direitos Fundamentais. Tradução por Virgílio Afonso da Silva. São Paulo: Editora Malheiros, 2008.

ATKINSON, Anthony B. Desigualdade: o que pode ser feito? Trad. Elisa Câmara. São Paulo: Leya, 2015.

ÁVILA, Humberto. Teoria dos princípios: da definição à aplicação de princípios jurídicos. 4. ed. São Paulo: Malheiros, 2005.

. Teoria da Igualdade Tributária. São Paulo: Malheiros, 2009.

Revista de Finanças Públicas, Tributação e Desenvolvimento, v. 6, n. 7, julho/dezembro, 2018, p. 100-121. 
BARROSO, Luís Roberto. Interpretação e aplicação da Constituição. 7. ed. São Paulo: Saraiva, 2009.

BRASIL. Supremo Tribunal Federal. Recurso Extraordinário $\mathrm{n}^{\circ}$ 153.771-MG. Recorrente: José Tarcizio de almeida Melo; Recorrido: Município de Belo Horizonte. Relator: Min. Moreira Alves. Brasília, 20/11/96. Disponível em http://redir.stf.jus.br/paginadorpub/paginador.jsp?docTP=AC\&docID=211634. Acesso em: 26 set. 2017.

. Supremo Tribunal Federal. Recurso Extraordinário no 234.105-3 SP. Recorrentes: Adolfo Carlos Canan e outra. Recorrido: Município de São Paulo. Rel.: Min. Carlos Velloso. Brasília, 08/04/99. Disponível em http://redir.stf.jus.br/paginadorpub/paginador.jsp?docTP=AC\&docID=254529 . Acesso em: 26 set. 2017.

. Supremo Tribunal Federal. Recurso Extraordinário n ${ }^{0}$ 562.045-RS. Recorrentes: Estado do Rio Grande do Sul. Recorrido: Espólio de Emília Lopes de Leon. Relator: Min. Ricardo Lewandowski. $\quad$ Brasília, 06/02/2013. $\quad$ Disponível em http://redir.stf.jus.br/paginadorpub/paginador.jsp?docTP=AC\&docID=630039. Acesso em: 26 set. 2017.

BUFFON, Marciano; MATOS, Mateus Bassani de. Tributação no Brasil do século XXI: uma abordagem hermeneuticamente crítica. Porto Alegre: Livraria do Advogado, 2015.

CARVAlHO JR., Pedro Humberto Bruno de. Aspectos distributivos do IPTU e do patrimônio imobiliário das famílias brasileiras. Rio de Janeiro: IPEA, 2009.

CONSELHO DE DESENVOLVIMENTO ECONÔMICO E SOCIAL. Indicadores de iniquidade do Sistema Tributário Nacional - Relatório de Observação nº 2. 2. ed. Brasília, 2011.

CONTIPELLI, Ernani. Solidariedade social tributária. São Paulo: Almedina, 2010.

DWORKIN, Ronald. Levando os direitos a sério. Tradução: Nelson Boeira. 3. ed. São Paulo: WMF Martins Fontes, 2010.

$\overline{\text { Jarsey, }} 2006$.

Is democracy possible here?: principles foa a new debate. Princenton University Press: New

GALLEDO PERAGÓN, José Manuel. Los principios materiales de justicia tributaria. Granada, 2003.

GODOI, Marciano Seabra de. Tributo e Solidariedade Social. In: GRECO, Marco Aurélio; GODOI, Marciano Seabra de. (Org.). Solidariedade Social e Tributação. São Paulo: Dialética, 2005.

GRECO, Marco Aurélio. Solidariedade social e tributação. In: GRECO, Marco Aurélio; GODOI, Marciano Seabra de (Orgs.). Solidariedade social e tributação. São Paulo: Dialética, 2005, p. 168189.

HAYEK, Friedrich August von. Reexaminando a taxação progressiva. In. FERRAZ, Roberto. Princípios e Limites da Tributácição. Quartier Latin: São Paulo, 2005. 
LARENZ, Karl. Metodologia da ciência do direito. Tradução José Lamego. 3. ed. Lisboa: Fundação Calouste Gulbenkian, 1997.

MACEDO, Alberto. A progressividade fiscal nos impostos sobre a propriedade e a decisão do STF sobre o ITCMD. In: PARISI, Fernanda Drummond; TÔRRES, Heleno taveira; MELO, José Eduardo Soares de (Org.). Estudos de Direito Tributário em homenagem ao Professor Roque Antonio Carraza. São Paulo: Malheiros, 2014, v. 2, p. 269-292.

MOSCHETTI, Francesco. El Principio De La Capacidad Contributiva. In: AMATUCCI, Andrea (Org.). Tratado de Derecho Tributario, 2001, v. I.

MURPHY, Liam; NAGEL, Thomas. O Mito da Propriedade: os impostos e a justiça. São Paulo: Martins Fontes, 2005.

NABAIS, José Casalta. $O$ dever fundamental de pagar impostos: contributo para a compreensão constitucional do estado fiscal contemporâneo. Coimbra: Almedina, 2015.

OXFAM BRASIL. A distância que nos une: um retrato das desigualdades brasileiras. Disponível em: $<$ https://www.oxfam.org.br/sites/default/files/arquivos/Relatorio_A_distancia_que_nos_une.pdf > Acesso em: 26 set. 2017.

PALMEIRA, Marcos Rogerio. Direito Tributário versus Mercado: o liberalismo na reforma do estado brasileiro nos anos 90. Rio de Janeiro: Renovar, 2002.

PIKETTY, Thomas. O Capital no século XXI. Trad. Monica Baumgarten De Bolle. Rio de Janeiro: Intrínseca, 2014.

RECEITA FEDERAL. Carga tributária no Brasil 2014. Disponível em: http://idg.receita.fazenda.gov.br/dados/receitadata/estudos-e-tributarios-e-aduaneiros/estudos-eestatisticas/carga-tributaria-no-brasi1/29-10-2015-carga-tributaria-2014. Acesso em: 8 jul. 2016.

RIBEIRO, Ricardo Lodi. Temas de direito constitucional tributário. Rio de Janeiro: Lumen Juris, 2009.

SCHOUERI, Luís Eduardo. Direito Tributário. 7. ed. São Paulo: Saraiva, 2017.

TIPKE, Klaus. LANG, Joachim. Direito Tributário (Steurrecht). Volume I. Porto Alegre: Sergio Antonio Fabris Editor, 2008.

TORRES, Ricardo Lobo. Tratado de Direito Constitucional Financeiro e Tributário: Valores e princípios constitucionais tributários. Volume II. Rio de Janeiro: Renovar, 2014.

. O Poder de Tributar no Estado Democrático de Direito. In: TÔRRES, Heleno Taveira (Coord.). Direito e Poder. Estudos em homenagem a Nelson Saldanha. São Paulo: Manole, 2005. 